\title{
La relación entre el nivel de auto-eficacia y la capacidad de enfrentamiento, con el proceso de aculturación de los migrantes mexicanos en Estados Unidos
}

\author{
Gabriela Silva Muñoz, Patricia Ruiz de Santiago y Nevárez, \\ Alejandra Domínguez Espinosa, Alma Polo Velázquez
}

\begin{abstract}
Recibido: 26 de enero de 2009 Revisado: 30 de marzo de 2009 Aprobado: 6 de abril de 2009
\end{abstract}

\section{Resumen}

El fenómeno migratorio afecta a una gran parte de la humanidad que, por diferentes motivos, se ven en la necesidad de abandonar sus familias, sus tierras y sus culturas, para buscar diferentes alternativas de vida. El propósito principal de esta investigación fue conocer la relación que tiene la capacidad de enfrentamiento y el nivel de auto-eficacia de mexicanos migrantes en Estados Unidos, con la estrategia de aculturación que utilizan. Se seleccionaron 136 mexicanos y mexicanas residentes en el área de Nueva York. Se aplicaron las escalas de Estrategias de aculturación, Autoeficacia y la Escala Multidimensional y Multisituacional de Estilos de Enfrentamiento. Los resultados indicaron que entre más utilice una persona la estrategia de enfrentamiento directo, más fácil podrá experimentar un proceso de aculturación que promueva la integración y entre más estrategias de enfrentamiento evasivo utilice una persona, mayor será la tendencia a experimentar un proceso de aculturación que promueva la separación o marginación. Por otro lado, se encontró que la autoeficacia no se relaciona directamente con alguna estrategia de aculturación. Esto refuta la hipótesis planteada que indica que entre mayor autoeficacia tenga una persona, mayor será su tendencia a integrarse a una nueva cultura.

\section{Palabras clave}

Migrantes, aculturación, autoeficacia, estrategias de enfrentamiento.

* Gabriela Silva Muñoz, egresada de la Licenciatura en Psicología de la Universidad Iberoamericana, UIA. Asistente de investigación del proyecto: Dimensiones culturales y su influencia en el funcionamiento familiar de los migrantes mexicanos.

Patricia Ruiz de Santiago y Nevaréz, egresada de la Licenciatura en Psicología de la UIA. Asistente de investigación del proyecto: Dimensiones culturales y su influencia en el funcionamiento familiar de los migrantes mexicanos.

Alejandra Domínguez Espinosa, profesora-investigadora del Departamento de Psicología de la UIA. Líder de la línea de investigación Cultura, Evaluación e Intervención Psicológica, responsable del proyecto: Dimensiones culturales y su influencia en el funcionamiento familiar de los migrantes mexicanos, financiado por la Dirección de Investigación del a UIA. Correo electrónico: alejandra.dominguez@ uia.mx. Alma Polo Velázquez, profesora-investigadora del Departamento de Psicología del a UIA. Miembro de la Línea de investigación Cultura, Evaluación e Intervención Psicológica. 


\title{
The relation between self-effectiveness level and the capacity of confrontation, with the migrant process of acculturation of the Mexicans in the United States
}

\author{
Gabriela Silva Muñoz, Patricia Ruiz de Santiago y Nevárez, \\ Alejandra Domínguez Espinosa, Alma Polo Velázquez
}

\begin{abstract}
The migratory phenomenon affects a great part of the humanity that, by different reasons, sees itself in the necessity to leave their families, their earth and their cultures, to look for different alternatives from life. The main intention of this investigation was to know the relation that has the capacity of confrontation and the level of self-effectiveness of Mexican migrants in the United States, with the strategy of acculturation they use. 136 Mexican and Mexican residents in the area of New York were selected. Scales of Strategies of acculturation, Self-effectiveness and the Multi-dimensional and Multi- situational Scales of styles of confrontation were applied. The results indicated that the more a person uses the strategy of direct confrontation, will be easier to undergo an acculturation process that promotes integration and while more strategies of evasive confrontation uses a person, major will be the tendency to undergo an acculturation process that promotes the separation or marginalization. On the other hand, it was found that self-effectiveness is not related directly to some strategy of acculturation. This refutes the raised hypothesis that indicates that the greater self-effectiveness has a person, major will be his tendency to integrate to a new culture.
\end{abstract} Recibido: 26 de enero de 2009 Revisado: 30 de marzo de 2009

Key words

Migrant, acculturation, self-effectiveness, strategies of confrontation. 


\section{INTRODUCCIÓN}

El fenómeno migratorio afecta a una gran parte de la humanidad que, por diferentes motivos, se ven en la necesidad de abandonar sus familias, sus tierras y sus culturas, para buscar diferentes alternativas de vida. El migrante lleva consigo una mezcla de sueños, deseos, pesadillas, ilusiones, carencias y nostalgia. La migración significa el desplazamiento de población de un país a otro por causas económicas, sociales o políticas. Salgado de Snyder (2002) señala que el proceso de migración se inicia con la motivación para hacerlo, siendo que generalmente la motivación central de la mayoría de los hombres y mujeres es mejorar sus condiciones de vida y las de su familia por medio de un mayor ingreso económico.

La movilidad geográfica de mexicanos a Estados Unidos es un proceso social y económico que ha transformado la vida de tanto mexicanos como de los americanos. A pesar de que la tradición de migración MéxicoEstados Unidos lleva un largo tiempo, la presencia de mexicanos en el país del norte continua siendo un tema central en la atmósfera política, económica y social de ambos países. Los mexicanos representan la mayor cantidad de población latina que vive en los Estados Unidos de América y, según cifras del Consejo Nacional de Población (CONAPO, 2008a), en lo que va del año se estima que poco más de 11,8 millones de personas nacidas en México residen en ese país y representan el $4 \%$ de la población total de la Unión Americana y cerca del 11\% de la población de México.

Actualmente, millones de campesinos mexicanos se trasladan del sur al norte; hombres, mujeres y niños que se van de su lugar de nacimiento, a fin de buscar mejores condiciones de vida, debido a que en su tierra prevalece el desempleo, la violencia, el hambre y la pobreza. La mayoría de estas personas migran de forma ilegal, arriesgando sus vidas por los terribles cruces y vías por los que tienen que pasar (Rogler, 1994). El catalizador principal de la corriente migratoria radica en los factores de demanda (atracción) de ofertas de trabajo. Los trabajadores mexicanos son un componente esencial en el trabajo manual realizado en Estados Unidos (CITA). Asimismo, las constantes crisis por las que atraviesa la economía mexicana han provocado que los factores de la oferta (expulsión) cobren importancia. De acuerdo con los datos de la Oficina de Estadísticas Laborales de Estados Unidos, entre 1998 y 2008 (CONAPO, 2008b) habrá un excedente de 5 millones de empleos, de los cuales un $57 \%$ requerirán personal con una escolaridad de secundaria-preparatoria. Precisamente, estas posibilidades de empleo son los atractivos para que un gran porcentaje de la población mexicana decida irse y no solamente aquéllos con ese nivel de escolaridad, ya que se han registrado flujos migratorios de personas con niveles superiores de estudio que ocupan esas mismas plazas.

Desde el punto de vista político y económi$\mathrm{co}$, los flujos migratorios de indocumentados hacia los Estados Unidos son una fuente de conflicto para los nacionales, ya que existe la percepción de que los migrantes reemplazan los puestos de trabajo de los nativos, viven de la seguridad social gratuita, no se asimilan a la cultura ni aprenden el idioma y son un foco delictivo en potencia (CITA); sin embargo, esto resulta paradójico, ya que, como indican Aguilera-Guzmán, Carreño y Juárez (2004), los trabajadores migrantes constituyen un sector esencial 
para la economía de este país, ya que los residentes no desean realizar los trabajos arduos y mal pagados, que son ocupados por los propios migrantes.

Por otro lado, Aguilera-Guzmán (2007) señala que los ataques terroristas perpetuados el 11 de septiembre de 2001 marcaron un cambio importante en la política migratoria de Estados Unidos, lo que dificulta la obtención de visas de trabajo y de turistas, por lo que el número de personas que recurrieron al cruce ilegal de fronteras aumentó, lo cual trajo consigo un aumentó en la peligrosidad y cobro de los cruces y alteró la circularidad del flujo al aumentar el tiempo promedio de estancia de los inmigrantes mexicanos de 1,7 a 3,5 años. Día tras día salen de México seiscientas personas en promedio, quienes buscan cruzar la frontera norte, lo cual representa una cifra anual de 600 mil mexicanos.

Desde el punto de vista psicológico, se ha documentado que los mexicanos migrantes que logran pasar la frontera sufren por las condiciones adversas asociadas con la nueva condición social a la que se enfrentan, la cual frecuentemente está asociada con ocupaciones de bajo reconocimiento social, desempleo, bajos salarios, falta de servicios básicos y discriminación. Cuando esto ocurre, las personas están más propensas a tener trastornos psicológicos, entre los que se resalta el estrés ocasionado por la no comprensión de la nueva cultura (Salgado de S., Díaz-P., Acevedo \& Natera, 1996).

La aculturación comprende cambios adaptativos de los individuos que entran en contacto con otras culturas, siendo que la variación en estos cambios depende, en gran medida, de las similitudes o disparidades entre la cultura receptora y la del migran- te, incluyendo características particulares, tiempo de exposición, nivel de educación y habilidades, sexo, edad, lenguaje, raza y fortaleza psicológica y espiritual, política y actitudes sociales de la cultura receptora (Berry, Phinney, Sam \& Vedder, 2006a; Sam \& Berry, 2006). Estos cambios adaptativos no son solamente vistos como la adaptación de un individuo a las normas y al estilo de vida de la cultura receptora, sino que también considera cómo es que los individuos dentro de esta nueva cultura la influencian (Valencia \& Johnson, 2008).

La literatura señala que existen cuatro tipos de estrategias de aculturación:

- Asimilación: cuando una persona no desea mantener su cultura heredada y anda en búsqueda de integrarse a otra cultura en una sociedad más grande.

- Integración: la persona tiene el interés de mantener su cultura original y además interactuar con otros grupos.

- Separación: aquí la persona se mantiene en su cultura original y al mismo tiempo desea evadir la interacción con otros.

- Marginación: hay poco interés por mantener la propia cultura y también por relacionarse con otros grupos (Berry, Segall \& Kagitçibasi, 1997).

Según algunos estudios recientes, la estrategia de aculturación más adecuada en términos de salud mental y física es la de integración (Berry, Phinney, Sam \& Vedder, 2006b) Para que se pueda dar una aculturación de este tipo en personas migrantes, el apoyo práctico y emocional intrafamiliar es el recurso más importante (Greeff \& Holtzkamp, 2007). Se ha demostrado que existen factores muy importantes como: la cantidad de tiempo que ha pasado desde la migración, 
la posición en la ciudadanía y la participación política, el uso del idioma, la religión, y la proporción de amigos y redes sociales con que se cuenten, para determinar la facilidad de adaptación de los inmigrantes a un nuevo país (Phythian, Walters \& Anisef, 2007).

Dentro del proceso de aculturación, un elemento importante es aprender el idioma del país receptor, ya que la resistencia de las personas a utilizar un idioma extranjero resulta un obstáculo para el aprendizaje cultural que se requiere en la aculturación (Miranda \& Umhoefer, 1998). Otras de las características para que se dé la adaptación se tienen: sobreponerse al dolor de las pérdidas y la alteración causada por dejar el país de origen y adueñarse de las condiciones de reasentamiento asociadas con la migración (Greeff \& Holtzkamp, 2007). Asimismo, para poder lograr un proceso de aculturación adecuado se requieren diversas características personales, dentro de las cuales se encuentra las estrategias de enfrentamiento y la autoeficacia. Estas dos herramientas son de vital importancia, ya que para enfrentar todas las adversidades que se puedan presentar durante el proceso de adaptación, se necesita confianza y capacidad de enfrentamiento. Primero se mencionará literatura referente a la autoeficacia.

Existen estudios afines con autoeficacia en poblaciones migrantes relacionados con variables como control de ansiedad, desarrollo cognitivo, la forma en que influyen en la memoria o en áreas sociales. Sin embargo, hay muy poca información que relacione la autoeficacia con el grado de adaptación de un individuo por causas de migración y sus estrategias de enfrentamiento. Etter, Bergman, Humair y Perneger (2000) señalan que la autoeficacia significa "la confianza que uno mismo tiene para realizar un comportamiento en determinada situación", la cual depende de experiencias pasadas, la influencia de las demás, el estado mental y psicológico, y las expectativas que se tengan.

La autoeficacia también se ha relacionado de manera positiva con beneficios de salud, empoderamiento y capacidad de "autodeterminación" (Takahashi, Magalon, DeBell \& Fasudhani, 2006).

Se ha visto con poblaciones latinas que entre mayor sea el nivel de aculturación de una persona, mayor autoconfianza tendrá para realizar exitosamente una tarea. Individuos que han logrado, entre otras características, ser bilingües e integrarse a su nuevo medio tienen mayor nivel de autoeficacia que quienes permanecen marginados (Miranda \& Umhoefer, 1998).

Se sabe que la confianza para alcanzar ciertas metas de manera exitosa, le permite a la persona tomar decisiones con mayor determinación y con mayor seguridad. Endler, Speer, Johnson, y Flett (2001) definieron la autoeficacia como un constructo que va de la mano con ciertas características de personalidad que facilitan realizar una tarea o ejecutar un determinado comportamiento exitosamente. Esto resulta importante en el tema de la migración, porque las personas que tienen mayor nivel de autoeficacia pueden tomar decisiones con mayor seguridad y determinación que aquéllas que no y, por tanto, cuentan con mayor cantidad de recursos internos que logren un mejor nivel de aculturación. Según estos autores la autoeficacia tiene tres componentes: 1) magnitud: de acuerdo con el tamaño y dificultad del problema; 2) fuerza: la necesaria para salir 
del problema; 3) generalidad: para poder aplicar la misma habilidad en la resolución de otro problema. Entre mayor sea la magnitud, fuerza y capacidad para generalizar la autoeficacia utilizada en una determinada situación a otros eventos, mayor será la capacidad de un individuo de adaptarse a su nuevo medio.

Un aspecto importante de la autoeficacia, el cual ha sido poco explorado, es la autoeficacia emocional, la cual es definida como la propia capacidad con que se percibe el individuo para enfrentar emociones negativas, es decir, la habilidad que un individuo tiene para evitar estados emocionales negativos como prevenir estrés y evitar pensamientos negativos; o poder regresar a un estado tranquilo de ánimo cuando se experimente angustia o dolor, por ejemplo, hablándose a uno mismo para calmarse, distrayéndose con pasatiempos, pensando positivamente, etc. (Valois, Umstattd, Zullig \& Paxton, 2008). Bandura (1986, en Camgoz, Selin, Tektas \& Metin, 2008) propuso que las propias expectativas de eficacia de las personas determinan, en gran medida, las metas que se proponen, las elecciones que se toman, la voluntad para esforzarse y la perseverancia.

En el caso de la migración, la autoeficacia puede ser muy útil para enfrentar situaciones adversas, ya que una persona con mayor cantidad de recursos internos, podrá experimentar un proceso de aculturación de manera más rápida que alguien carente de ellos. Como lo indican Bandura y Locke (2003), entre más confianza tenga una persona en su propia autoeficacia, mayor será el éxito que tenga en el rendimiento de tareas cognitivas y en la intensidad de participación en actividades recreativas.
En el caso de nuestra investigación, estas herramientas les ayudarían a los migrantes a tomar mejores decisiones que impliquen procesos cognitivos, pensamientos más elaborados y, al mismo tiempo, poder disfrutar de actividades que les permitan relajarse y reducir niveles de estrés, lo cual les da una mejor calidad de vida. Por tanto, el bienestar subjetivo de la persona favorece a un mejor rendimiento en tareas cognoscitivas y recreativas. De tal suerte que se supondría que niveles adecuados de autoeficacia le proporcionan al individuo herramientas para tener un mejor proceso de aculturación si existe el deseo de migrar.

Como se mencionó anteriormente, las estrategias de enfrentamiento que cada persona tiene son de vital importancia para que se dé un adecuado proceso de aculturación. Entre mejores estrategias de enfrentamiento se tengan, mejor será la adaptación psicológica y sociocultural. El enfrentamiento es definido como aquellos esfuerzos cognitivos y conductuales constantemente cambiantes que se desarrollan para manejar las demandas específicas externas o internas que son evaluadas como excedentes o desbordantes de los recursos del individuo. El enfrentamiento es un proceso cambiante en el que el individuo, en determinados momentos debe contar principalmente con estrategias defensivas y en otros con estrategias que sirvan para resolver problemas; todo ello a medida que va cambiando su relación con el entorno (Lazarus \& Folkman, 1984).

Siguiendo en esta línea, el enfrenamiento permite mantener o aumentar el control de estresores externos o internos y regular el propio comportamiento, pensamientos y emociones (Skinner \& Wellborn, 1994). 
Aunque la literatura sobre este tema es abundante, existe muy poca información que hable acerca de la relación entre la capacidad de enfrentamiento y migración. Sin embargo, Lazarus y Folkman (1984) señalan que las personas que hacen uso de adecuadas estrategias de enfrentamiento en situaciones generadoras de estrés, tienen la determinación de generar una respuesta positiva.

Es preciso definir que las estrategias de enfrentamiento son los procesos concretos que se utilizan en cada contexto y pueden ser altamente cambiantes dependiendo de las condiciones desencadenantes (Fernández-Abascal, 1997). Los estudios llevados a cabo en México han llevado al desarrollo de diversas escalas, en las cuales se ha evidenciado la existencia de algunos tipos de enfrentamiento (Góngora \& Reyes, 1998) como son: enfrentamiento evasivo, que implica evadir la confortamiento de los problemas a través de tener fe de que las cosas se pueden resolver por sí solas, y de que es mejor que el tiempo se encargue de ellas. Aquí la persona evita, escapa o minimiza el problema. Enfrentamiento apoyo social: se responde a los problemas diarios a través de la comprensión de los demás, de buscar consejo y apoyo a través de los otros, evitando pensar en una solución por ellos mismos. Enfrentamiento directo-revalorativo: busca aprender de los conflictos y encontrarles lo positivo. Trata de analizarlos para implementar nuevas estrategias para llegar a diferentes resultados. Enfrentamiento directo: trata de resolver los problemas de manera directa y sin rodeos, planteando y actuando al mismo tiempo, y poniendo mucho empeño y esfuerzo para que se solucionen.

Noh, Beiser, Kaspar, Hou \& Rummens (en Roesch, Wee \& Vaugh, 2006) señalan que individuos procedentes de culturas colec- tivistas tienen mayor predisposición a utilizar estrategias de enfrentamiento evasivo que directo y la cultura mexicana tiende al colectivismo. Además, sugieren que el incremento de la aculturación en la sociedad dominante receptora está relacionado con un aumento en las competencias y nivel de empoderamiento de las personas, es decir, individuos mejor adaptados dentro de la nueva cultura tienen los recursos psicológicos, sociales y económicos para enfrentar problemas.

Roesch, Wee \& Vaugh (2006) dicen que el enfrentamiento directo se utiliza en situaciones en las que la persona se centra en poder controlar la reacción emocional provocada por el estrés así como enfocarse en remover la fuente del problema. Dentro de las estrategias de enfrentamiento directo se tiene: enfrentamiento centrado en el problema y enfrentamiento centrado en la emoción.

Lazarus (1993 en Alumran \& Punamäki, 2008) menciona que tanto la naturaleza del estrés como las características de personalidad van a determinar la estrategia de enfrentamiento por seguir ante un conflicto. La gente tiende a utilizar estrategias de enfrentamiento directo cuando la situación estresante parece controlable; mientras que en situaciones que son percibidas como fuera de control se utiliza enfrentamiento evasivo. Alumran \& Punamäki (2008) encontraron que las personas con un estilo de enfrentamiento directo poseen mayor inteligencia emocional y adaptación, aunque no necesariamente un mejor manejo del estrés, mientras que personas que utilizan estrategias de enfrentamiento pasivo poseen menores niveles de adaptación y altos niveles de control de estrés. En lo que a inteligencia emocional se refiere, se ha visto que ésta puede 
resultar en una precondición para solucionar problemas eficientemente. La estrategia de enfrentamiento directo está relacionada con una personalidad con características de optimismo, autoestima, fortaleza y confianza en sí mismo para resolver problemas, como parte de la inteligencia emocional.

Así como la personalidad determina, en gran parte, el tipo de estrategia de enfrentamiento por seguir, el ambiente también tiene su propia importancia. Entre más se perciben abusos, vulnerabilidad familiar, discriminación, dificultades en el manejo del idioma y miedo a la deportación, menos se recurre a estrategias directas de enfrentamiento y se tiende en mayor medida a estrategias pasivas. Basándonos en esto, este estudio propone que entre más estrategias de enfrentamiento directo tenga una persona para enfrentar una situación difícil como lo es la migración, más fácil será el proceso de aculturación.

Esta investigación tiene aplicaciones en cuanto a lo social, ya que si se logran comprobar nuestras hipótesis, se puede saber con mejor exactitud si la persona se adaptará adecuadamente al país receptor. Esto puede llevar a diseñar programas preventivos o de intervención para fortalecer la autoeficacia y la capacidad de enfrentamiento en los migrantes y así poder tener una mejor calidad de vida, por lo que el objetivo de este estudio fue conocer la relación que tiene la capacidad de enfrentamiento y la autoeficacia de mexicanos migrantes en Estados Unidos, con la estrategia de aculturación que ponen en práctica. De tal manera se desprenden las siguientes hipótesis del estudio:

- Entre mejores capacidades de enfrentamiento y autoeficacia tenga una persona, más fácil será su proceso de aculturación a una nueva cultura.

- Entre más utilice una persona la estrategia de enfrentamiento directo, más fácil podrá experimentar un proceso de aculturación que promueva la integración.

- Entre más estrategias de enfrentamiento evasivo utilice una persona, mayor será la tendencia a experimentar un proceso de aculturación que promueva la marginación.

- A mayor autoeficacia tenga una persona, mayor será su tendencia a integrarse a una nueva cultura.

\section{Método}

\section{Participantes}

Mediante un muestreo de tipo no probabilístico, se seleccionaron 136 mexicanos residentes en Estados Unidos al momento de la investigación en el área de Nueva York (NY), con un rango de edad entre dieciocho a sesenta y nueve años ( $\mu=29,65, \sigma=7,559$ años), hombres $(43 \%)$ y mujeres (57\%) que de manera voluntaria y bajo consentimiento informado accedieron a participar, no importando su estado legal. Estos mexicanos nacieron y vivieron en México durante al menos 10 años.

\section{Instrumentos}

La recolección de datos se llevó a cabo mediante la aplicación de tres escalas, las cuales se encontraban en un formato Likert con cinco opciones de respuesta, siendo 1 "totalmente en desacuerdo" y 5 "totalmente de acuerdo".

La primera, la Escala Multidimensional y Multisituacional de Estilos de Enfrentamiento (Góngora \& Reyes, 1998) versión con vein- 
ticinco reactivos, que evalúo el rasgo general de enfrentamiento. Para esta escala se obtuvo un $\alpha=.90$, midiendo los siguientes estilos de enfrentamiento: evasivo, directo revalorativo, emocional evasivo, emocional negativo, directo, evasivo constructivo y de apoyo social. La segunda escala evalúa la Autoeficacia conformada por nueve reactivos, basada en el trabajo desarrollado por Bandura (2001), con un índice $\alpha=.709$ siendo unidimensional. La tercera escala midió las estrategias de aculturación propuestas por Berry (Berry et al., 2006b) que divide a las estrategias en integración, asimilación, separación y marginación. Adicionalmente, se contó con una sección de datos sociodemográficos que incorporaba preguntas referentes a edad, género, país y estado de nacimiento, edad de migración, quién tomó la decisión de la migración, por quién fue recibido al llegar a Estados Unidos, si es o no ciudadano americano y religión.

\section{Procedimiento}

Se realizó el levantamiento de datos en la ciudad de Nueva York, en los Estados Unidos de América en las oficinas del Consulado Mexicano y en organizaciones sociales que trabajan con migrantes. Al inicio de las aplicaciones se explicó de manera general los objetivos del estudio y se aseguró el anonimato de los participantes, mediante un consentimiento informado, indicándoles que los resultados se utilizarían con fines únicos y exclusivos de investigación. Esto fue posible, ya que se cuenta con un acuerdo de colaboración vigente entre el Departamento de Psicología de la Universidad Iberoamericana con el Consulado Mexicano. Las aplicaciones se llevaron a cabo de manera individual y colectiva, con una duración promedio de $45 \mathrm{~min}$.

\section{Resultados}

Para probar las hipótesis planteadas se llevaron a cabo análisis de correlación bivariada producto momento de Pearson, así como análisis segmentados para hombres y mujeres. Para la variable Autoeficacia se obtuvo una correlación baja positiva con el estilo de Enfrentamiento directo de 236, p<.01, lo que indica que la capacidad de solucionar problemas de manera directa, sin rodeos y poniéndole mucho empeño, se relaciona con la confianza que uno tiene en sus propias capacidades para realizar un comportamiento adecuado para una determinada situación. El estilo de Enfrentamiento directo también tiene una correlación baja positiva con la estrategia de aculturación Integración, siendo ésta de 209, p<.05, lo que indica que cuando un migrante se preocupa por conservar sus tradiciones culturales originarias y adaptarse a las tradiciones del país receptor, es probable que tenga una buena capacidad de solucionar problemas de manera directa.

Esta correlación aprueba una de las hipótesis planteadas, ya que entre más utilice una persona la estrategia de enfrentamiento directo, más fácil podrá experimentar un proceso de aculturación que promueva la integración. El estilo de enfrentamiento Directo-revalorativo tiene una correlación baja negativa con la estrategia de aculturación Separación, $\mathrm{r}^{2}=$-. 202, p<.01, lo que indica que los migrantes que solamente quieren mantener sus tradiciones culturales originarias y no adaptarse a las del país receptor, no buscan aprender de los conflictos, no evalúan las situaciones de manera positiva ni perciben diferentes alternativas para la solución de problemas. 
La variable Autoeficacia no se relaciona directamente con ninguna estrategia de aculturación, lo que indica que la confianza que uno tiene en sus propias capacidades para realizar un comportamiento adecuado para una determinada situación puede estar presente en todas y cada una de las estrategias de aculturación, es decir, que no necesariamente está relacionada con alguna estrategia en específico. Esto refuta la hipótesis planteada que indica que entre mayor autoeficacia tenga una persona, mayor será su tendencia a integrarse a una nueva cultura.

Se realizaron los mismos análisis de correlación, tanto para el grupo de hombres como para mujeres, encontrándose lo siguiente:

- La variable Autoeficacia tiene una correlación baja positiva con el estilo de Enfrentamiento directo de. 355, p<.05 en los hombres, lo que indica que la población migrante del sexo masculino tiene mayor capacidad para enfrentar los problemas de manera directa y mayor confianza en sus propias capacidades para realizar un comportamiento adecuado en una determinada situación que el sexo femenino.

- La estrategia de aculturación Asimilación tiene una correlación baja negativa con el estilo de enfrentamiento Evasivo constructivo, $\mathrm{r}^{2}=-.252, \mathrm{p}<.05$, en las mujeres, lo que indica que cuando una mujer no desea mantener su cultura heredada y anda en búsqueda de integrarse a otra cultura en una sociedad más grande, tampoco tiene fe en que las cosas se puedan resolver y se acostumbra a actuar impulsivamente. Esto quiere decir que una mujer migrante al querer integrarse a la nueva cultura, actúa sin pensar y se deja llevar por lo primero que piensa.
- La estrategia de aculturación Integración tiene una correlación baja positiva con el estilo de Enfrentamiento directo, $\mathrm{r}^{2}=$ $233, p<.05$, en las mujeres, lo que indica que la población femenina migrante que tienen el interés de mantener su cultura original y además el hecho de interactuar con otros grupos hace enfrenten los problemas de forma directa, poniendo gran empeño para la solución de problemas. Este estilo de enfrentamiento directo es de gran ayuda para que se pueda dar la integración tanto de la cultura originaria como del país receptor. Esta correlación comprueba la hipótesis planteada, ya que entre más utilice una persona la estrategia de enfrentamiento directo, más fácil podrá experimentar un proceso de aculturación que promueva la integración.

- La estrategia de aculturación Marginación tiene una correlación baja negativa con el estilo de Enfrentamiento directo, $\mathrm{r}^{2}$ $=-$. 272, $\mathrm{p}<.05$, en las mujeres, lo que indica que la mujer que tiene poco interés por mantener la propia cultura y también por relacionarse con otros grupos, no enfrenta los problemas de manera directa y no pone empeño en su solución. Es decir, que las mujeres que no saben enfrentar los problemas sin evadirlos, probablemente no se adaptarán a la nueva cultura ni mantendrán la originaria.

- La estrategia de aculturación Separación tiene una correlación baja negativa con el estilo de Enfrentamiento directo, $\mathrm{r}^{2}=$ -. 245, p<.05, en las mujeres, lo que indica que la mujer migrante que se mantiene en su cultura original y al mismo tiempo desea evadir la interacción con otros tampoco enfrenta los problemas de manera directa, prefiere evadirlos. De acuerdo con las hipótesis planteadas y con el marco teórico, es lógico pensar 
que las personas que utilizan como estrategia de aculturación tanto la marginación como la separación no saben enfrentar los problemas y no se esfuerzan para solucionarlos.

- La estrategia de aculturación Separación tiene una correlación baja negativa con el estilo de Enfrentamiento directo-revalorativo, $\mathrm{r}^{2}=-. .254, \mathrm{p}<.05$, en las mujeres, lo que indica que la población migrante femenina que se mantiene en su cultura original y al mismo tiempo desea evadir la interacción con otros no busca aprender de los conflictos y encontrarles lo positivo. Como se ha mencionado anteriormente, utilizar la separación como estrategia de aculturación quiere decir que la persona no sabe enfrentar los problemas y esto tiene como consecuencia que no se pueda adaptar a la cultura del país receptor.

\section{Discusión}

El propósito principal de esta investigación fue conocer la relación que tiene la capacidad de enfrentamiento y el nivel de autoeficacia de mexicanos migrantes en Estados Unidos, con la estrategia de aculturación que utilizan. El objetivo se cumplió al comprobar la relación que considerábamos existente entre nuestras variables.

Para la variable Autoeficacia se obtuvo una correlación baja positiva con el estilo de Enfrentamiento directo, el cual, a pesar de ser una asociación baja, resulta coherente con el marco conceptual (Bandura \& Locke, 2003), que indica que enfrentar de manera efectiva un problema, impacta en el nivel de confianza autogenerado al obtener resultados positivos en cada ocasión.
El estilo de Enfrentamiento Directo también tiene una correlación baja positiva con la estrategia de aculturación Integración, siendo que se aprueba una de las hipótesis planteadas, ya que entre más utilice una persona la estrategia de enfrentamiento directo, más fácil podrá experimentar un proceso de aculturación que promueva la integración. (Berry et al., 2006b) precisamente indican que la estrategia más adecuada para una buena salud mental es la integración.

El estilo de Enfrentamiento directo-revalorativo tiene una correlación baja negativa, lo que resulta coherente con el marco conceptual, ya que los migrantes que no buscan enfrentar los conflictos y aprender de ellos, se les hace mucho más difícil adaptarse a una nueva cultura, porque no están acostumbrados a la solución de problemas que puedan llevar a una adaptación a la cultura del nuevo país. Berry et al. (2006b) indican que la estrategia de separación es la que ocupa el tercer escalón en cuestiones de adaptación psicológica.

Los resultados de este estudio indicaron que, efectivamente, existe una relación entre el estilo de enfrentamiento directo y la estrategia de aculturación que promueve la integración. Este resultado comprueba una de las hipótesis principales, la cual se sustenta en la idea de que la estrategia de aculturación más adecuada en términos de salud mental y física es la de integración (Berry et al., 2006b). Ésta se relaciona en buena medida con un estilo de enfrentamiento directo, el cual implica una serie de características de personalidad como son la inteligencia emocional y la adaptación (Alumran \& Punamäki, 2008). Estas dos características de personalidad le permiten al sujeto afrontar la problemática directamen- 
te y poder integrarse a la sociedad receptora, sin tener repercusiones en su salud física y psicológica. Este resultado se contrapone a lo que Noh, Beiser, Kaspar, Hou \& Rummens (en Roesch, Wee \& Vaugh, 2006) señalan: individuos procedentes de culturas colectivistas, tienen mayor predisposición a utilizar estrategias de enfrentamiento evasivo que directo, y la cultura mexicana tiende al colectivismo.

El estilo de Enfrentamiento directo-revalorativo se correlaciona con la estrategia de aculturación separación. Este hallazgo comprueba la hipótesis planteada en el presente estudio, lo cual reitera el hecho de que la asimilación y la separación tienen un perfil en común, el cual incluye ideas autoritarias y etnocéntricas (Bourhis \& Dayan, 2004). Estas ideas son experimentadas por las personas nativas del lugar, pero transmitiéndolas a los inmigrantes, quienes se sienten incómodos y aislados ante una actitud de rechazo. Los inmigrantes que como estrategia de aculturación utilizan la separación evitan relacionarse con personas del país receptor, por tanto, se mantienen al margen de su nueva cultura, presentando problemas de adaptación. Torres \& Rollock (1979) explican que los estilos de enfrentamiento más pasivos, como es el caso del enfrentamiento directo-revalorativo, son más consistentes con la cultura tradicional, como lo es la cultura mexicana, pero que no son ni tan adaptativas ni competentes en la corriente central de la nueva cultura y no proveen los recursos necesarios para adaptarse a las demandas de la vida en la sociedad norteamericana.

Cabe aclarar que a pesar de que este estudio solamente engloba las estrategias de enfrentamiento con respecto a la aculturación, la conceptualización de enfrentamiento fue tomada como un estilo de personalidad y no como una estrategia que se elige de acuerdo con las demandas del estrés y que dependiendo de la situación se enfrenta de diferente manera (Folkman \& Lazarus 1985, en Alumran \& Punamäki, 2008).

Otro de los resultados que resulta coherente con el planteamiento de la investigación es la relación existente entre autoeficacia y el estilo de enfrentamiento directo. Alumran y Punamäki (2008) afirman que estrategias de enfrentamiento directo están relacionadas con una personalidad con características de optimismo, autoestima, fortaleza y autoconfianza para resolver problemas; encontramos que esa confianza en sí mismo se puede llamar autoeficacia, la cual se define como la convicción personal de que uno puede realizar con éxito cierta conducta requerida en una situación dada (Bandura, 1997). Cuando una persona tiene la convicción de que va a salir adelante, enfrentará los problemas de forma directa y sin rodeos, ya que tiene entre otras herramientas internas, la confianza para salir triunfante en una situación difícil, como lo es el tenerse que adaptar a una nueva cultura.

Endler et al. (2001) definieron la autoeficacia como un constructo que va de la mano con ciertas características de personalidad que facilitan realizar una tarea o ejecutar un determinado comportamiento exitosamente. Esto resulta importante en el tema de la migración, porque las personas que tienen mayor nivel de autoeficacia pueden tomar decisiones con mayor seguridad y determinación que quienes no y, por tanto, cuentan con mayor cantidad de recursos internos que logren un mejor nivel de aculturación. En el presente análisis no se encontró rela- 
ción entre autoeficacia y aculturación, contraponiéndose a lo que cabría esperar, según Endler et al (2001). Esto refuta una de las hipótesis principales, la cual planteaba que entre mayor autoeficacia tenga una persona, mayor será su tendencia a integrarse a una nueva cultura.

Pasando al análisis por género, se hizo una comparación de la muestra entre mujeres y hombres y se encontraron algunos resultados importantes. En cuanto a la relación de autoeficacia y estilos de enfrentamiento el estudio mostró que las mujeres utilizan un estilo evasivo, mientras que los hombres lo utilizan de manera directa. Este resultado concuerda con lo que Alumran y Punamäki (2008) señalan. Las mujeres normalmente utilizan estilos de enfrentamiento evasivos, ya que en situaciones de estrés, recurren a culparse ellas mismas de lo sucedido, acuden a la utilización del pensamiento mágico y hacerse ilusiones; se retiran del problema y lloran. La imagen que se tiene del rol femenino de fortaleza y expresividad se puede deber a un estereotipo.

Mientras tanto, los hombres actúan y escogen un tipo de comportamiento de enfrentamiento directo. Esta diferencia de enfrentamiento se puede explicar en que las mujeres ventilan más fácilmente sus emociones y buscan la ayuda social (Carver, Scheier \& Weintraub 1989, en Alumran \& Punamäki, 2008), mientas que los hombres utilizan reestructuración cognitiva, escape, contención, distracción y concentración en actividades de relajación como forma de lidiar con el estrés (Compas et al., 2001; en Alumran \& Punamäki, 2008). Otra característica que puede influir sensiblemente en la relación entre estas dos variables, es que las mujeres dirigen su confianza y atribuyen sus logros a situaciones externas, mientras que los hombres confían en sus propias habilidades (Boggiano \& Barrett, 1991; en Camgoz, Tektas, \& Metin, 2008).

Para cerrar, los resultados generales de la presente investigación fueron congruentes a las hipótesis planteadas y a otras investigaciones del campo de la psicología transcultural. Cabe decir que a pesar de que el estudio contó con algunas limitaciones -las cuales pudieron haber sesgado los resultados-, se abre la posibilidad de seguir investigando sobre esta línea para poder intervenir directamente con la población haciendo, por ejemplo, programas de prevención, ya que contamos con suficientes indicadores para poder aseverar que entre mayor capacidad de solucionar problemas de manera directa tenga una persona, mayor facilidad de integración en la aculturación. Esto deja un campo de trabajo enorme con niños y adolescentes mexicanos que tengan deseos o necesidad de emigrar.

\section{Conclusión}

Es este estudio se relacionaron las estrategias de aculturación con los estilos de enfrentamiento que utiliza cada persona. Los resultados indicaron que entre más utilice una persona la estrategia de enfrentamiento directo, más fácil podrá experimentar un proceso de aculturación que promueva la integración y entre más estrategias de enfrentamiento evasivo utilice una persona, mayor será la tendencia a experimentar un proceso de aculturación que promueva la separación o marginación. Estos resultados comprueban las hipótesis planteadas.

Los resultados muestran que las mujeres tienen una mayor tendencia a desarrollar 
un estilo de enfrentamiento evasivo y los hombres a desarrollar uno directo. Alumran y Punamäki (2008) señalan: las mujeres normalmente utilizan estilos de enfrentamiento evasivos, ya que en situaciones de estrés, recurren a culparse ellas mismas de lo sucedido, acuden a la utilización del pensamiento mágico, se hacen ilusiones, se retiran del problema y lloran. Cabe mencionar que esto no ocurre siempre, depende, en gran medida, de las fortalezas de cada persona, pues una mujer con ganas de superación y capacidad de salir adelante, puede presentar un estilo de enfrentamiento directo. Al igual, un hombre con pocas fortalezas y pocas ganas de superación puede presentar un estilo de enfrentamiento evasivo.

Tanto la literatura como los resultados presentados en este estudio muestran la gran complejidad que presenta la experiencia de aculturación a un nuevo país. Salgado de Snyder (2002) señala que el proceso de migración se inicia con la motivación para hacerlo, siendo que generalmente la moti- vación central de la mayoría de los hombres y mujeres es mejorar sus condiciones de vida y las de su familia por medio de un mayor ingreso económico. Sin embargo, cuando inicia esta motivación, los migrantes difícilmente piensan en la complejidad de la experiencia de aculturación que van a vivir, solamente se centran en tener un mayor ingreso económico sin tener una visión de lo que realmente van a experimentar, ya que un cambio de país y de cultura no es nada fácil.

\section{LIMITANTES}

Parte de la explicación de los hallazgos resulta que el tamaño de muestra es limitado, por lo que las correlaciones posiblemente hayan resultado ser más bajas de lo que en realidad sugiere la literatura, adicional a que la muestra fue heterogénea $y$, posiblemente, haya diferencias intragrupales, debidas a la edad que impactan en los valores de correlación.

\section{REFERENCIAS}

Aguilera-Guzmán, R.M (2007). Algunas controversias y características actuales del fenómeno migratorio México-EUA. Salud Mental, 30, 81-86.

Aguilera-Guzmán, R.M., Carreño, M. \& Juárez, F. (2004). Características psicométricas de la CES-D en una muestra de adolescentes rurales mexicanos de zonas con alta tradición migratoria. $\mathrm{Sa}$ lud Mental, 27 (57-66).

Bandura, A. (2001). Social Cognitive Theory: An Agentic Perspective. Annual Review of Psychology, 52, 1-26.
Bandura, A. \& Locke, E.A. (2003). Negative Self-Efficacy and Goal Effects Revisited. Journal of Applied Psychology, 88 (1), 87-99.

Berry, J.W., Phinney, J.S., Sam, D.L., \& Vedder, P. (2006a). Immigrant Youth: Acculturation, Identity, and Adaptation. Applied Psychology: An International Review, 55 (3), 303-332.

Berry, J.W., Phinney, J.S., Sam, D.L., \& Vedder, P. (Eds.). (2006b). Immigrant Youth in Cultural Transition. Mahwah, NJ: Lawrence Erlbaum Associates. 
Berry, J.W., Segall, M.H. \& Kagitçibasi, C. (Eds.) (1997). Handbook of Cross Cultural Psychology (2 ed. Vol. 3).

CONAPO (2008a). Comunicado de prensa. Mexico. Recuperado de: http://www. conapo.gob.mx.

CONAPO (2008b). Migración México-Estados Unidos (pp. 11-13). Mexico, D.F. Recuperado de: http: //www. conapo. gob. mx/publicaciones/intensidadmig/ cap01. pdf.

Endler, N.S., Speer, R.L., Johnson, J.M. \& Flett, G.L. (2001). General Self-Efficacy and Control in Relation to Anxiety and Cognitive Performance. Current Psychology, 20 (1), 36-52.

Etter, J.F., Bergman, M.M., Humair, J.P. \& Perneger, T.V. (2000). Development and Validation of a Scale Measuring Self-Efficacy of Current and Former Smokers. Addiction, 95 (6), 901-913.

Fernández-Abascal, E.G. (1997). Estilos y estrategias de afrontamiento. En E.G. Fernández-Abascal, M.C. Montañés, F.P. Cantero \& F.M. Sánchez (Eds.). Cuaderno de Prácticas de Motivación y Emoción. Madrid: Pirámide.

Góngora, E. \& Reyes, I. (1998). El enfrentamiento a los problemas en jóvenes adultos yucatecos. En AMEPSO (Ed.). La psicología Social en México (Vol. 7, pp. 18-24). México.

Greeff, A.P. \& Holtzkamp, J. (2007). The Prevalence of Resilience in Migrant Families. Family and Community Health, 30 (3), 189-200.

Lazarus, R.S. \& Folkman, S. (Eds.) (1984). Stress, Appraisal, and Coping. New York: Springer.

Miranda, A. \& Umhoefer, D. (1998). Acculturation, Language Use, and Demo- graphic Variables as Predictors of the Career Self-Efficacy of Latino Career Counseling Clients. Journal of Multicultural Counseling \& Development, 26 (1), 39-52.

Phythian, K., Walters, D. \& Anisef, P. (2007). The Acculturation of Canadian Immigrants: Determinants of Ethnic Identification with the Host Society. Canadian Review of Sociology and Anthropology, 44 (1), 37-64.

Rogler, L.H. (1994). International Migration. A Framework for Directing Research. American Psychologist, 49, 701-708.

Salgado de Snyder, V.N. (2002). Research and Clinical Perspectives on Mexican Migration: Those who Go, those who Stay. Journal of Multicultural Nursing $\mathcal{E}$ Health, 8 (2), 23.

Salgado de Snyder, V.N., Díaz-Perez, M.J., Acevedo, A. \& Natera, L.X. (1996). Dios $y$ el norte: The perceptions of Wives of Documented and Undocumented Mexican Immigrants to the United States. Hispanic Journal of Behavioral Sciences, 18 (3), 283.

Sam, D.L. \& Berry, J.W. (2006). The Cambridge Handbook of Acculturation Psychology. Cambridge, UK: Cambridge University Press.

Takahashi, L. Magalon, M. DeBell, P. \& Fasudhani, A. (2006). HIV and Aids in Suburban Asian and Pacific Islander Communities: Factors Influencing SelfEfficacy in HIV Risk Reduction. 18(6), 529-545.

Valencia, E. \& Johnson, V. (2008). Acculturaton among Latino Youth and the Risk for Substance Use; Issues of Definition and measurement Journal of Drug Issues, 38 (1), 37-68. 